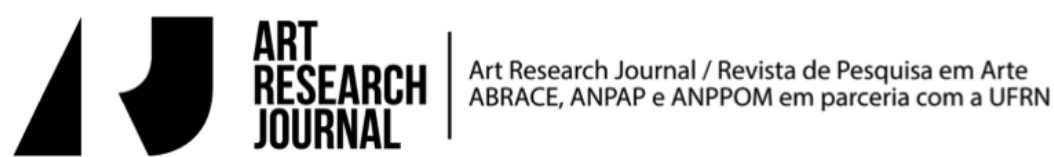

\section{INFRA-MINCE ou um murmúrio secreto ${ }^{1}$}

\author{
Patricia Dias Franca-Huchet \\ Universidade Federal de Minas Gerais, Brasil \\ patriciafranca.huchet@gmail.com
}

\section{Avant-Propos}

Quando minha mãe e Marcel começaram a se encontrar no início dos anos cinquenta, passava a maior parte do meu tempo na Universidade e não o encontrei imediatamente. Antes das férias de Natal, minha mãe me disse que Marcel viria fazer-nos uma visita em nossa casa de campo, em New Jersey. Eu cheguei, na véspera de Natal, e me dirigi diretamente ao salão para me apresentar e o encontrar. No entanto, o que eu vi em primeiro lugar foi a árvore de Natal. Não se precisava mesmo perguntar quem a havia instalado. Preferindo não se debater com o tradicional suporte de metal, procedimento sempre difícil e frustrante, ele havia fixado a base do tronco em uma das vigas do teto, operação que não deve ter-Ihe tomado mais do que cinco minutos. A árvore estava - bem entendido - de cabeça para baixo e, como ele observou com o seu humor habitual, essa orientação deixava mais espaço no solo para os presentes. Nós passamos um delicioso Natal juntos. [...] Em 1963, Marcel ficou encantado descobrindo que universitários estavam prontos a Ihe pagar para fazer uma conferência sobre ele mesmo. Com a ajuda de slides de seus trabalhos, ele relembrou a sua carreira e improvisou descrições de suas obras com muito humor. No final de uma de suas intervenções, perguntaram-Ihe se o non-sens que ele havia utilizado em suas obras eram um verdadeiro non-sens. Após um momento de perturbação, ele disse finalmente: "sens e non-sens são dois aspectos da mesma coisa e o non-sens tem o direito de viver". E ainda continuou: "Vocês entendem [veem] o que quero dizer?" Houve um momento de silêncio e de repente a sala o aplaudiu. (MATISSE,

Marcel Duchamp Notes, 1980, p. 9).2

1 Este texto é uma versão aprofundada e expandida da apresentação da comunicação Infra-mince ou como nomear o imperceptível no encontro anual da ANPAP: Associação Nacional dos Pesquisadores em Artes Plásticas, Belo Horizonte, 2014.

2 Paul Matisse (1933-), neto do pintor francês Henri Matisse (1869-1954) e enteado de Marcel Duchamp (1887-1968). 
O Infra-mince é um enunciado de Marcel Duchamp sobre um conjunto de notas evocando aspectos sensoriais e envolvendo percepções da ordem do sensível, da sensação, da linguagem e da complexidade dos jogos de palavra. No ano de 1998 escrevi um artigo sobre a denominação Infra-mince, mas com outro enfoque. ${ }^{3}$ Volto a este assunto que ainda penso em reiterar no futuro. Duchamp, partindo sempre do devir imperceptível da sensação, legou-nos pelas notas do Infra-mince aquilo que considero o seu maior segredo. Esse conceito - Infra-mince - contém toda a potência de seu trabalho e induz a pensarmos em seu caráter plástico, teórico e mesmo histórico. No âmbito da história da arte, poucos são os que se interessaram pela questão da invisibilidade e pela sensorialidade. Fazer obras com o quase nada, o quase imperceptível ou com o invisível - fumaça, respiração, hálito - parece-nos ser o desafio dos intangíveis que constituem um estado das coisas que participam de nosso entorno. A imaginação junto ao nada, ao quase nada, nos faz refletir, pensar, indagar. Implica formações de imagens, contemplação e a percepção de procedimentos visuais e plásticos. Acredito que aí está Marcel Duchamp, na exigência do cotidiano da vida, na brincadeira que podemos fazer, nos erros que podemos cometer - erros de apreciação, de compreensão das coisas na busca do entendimento de si mesmo e, sobretudo, no encarar uma prática artística que não seja simplesmente cercada de intenções formais, tentando encontrar um espaço onde o mistério traga algo a acrescentar, algo que não seja imediatamente visível. Falamos de uma obra jubilatória.

Duchamp propõe três maneiras de escrever o Infra-mince: grafando-o com uma

3 "Marcel Duchamp deixou-nos 46 notas que intitulou Infra-mince. Duchamp opera, em suas Notas, uma sutil dosagem entre aspectos lúdicos e hipersensíveis - ora sensitivos. [...] É sem dúvida seu caráter especulativo e irônico que lhe proporciona uma tonalidade ao mesmo tempo estética e com aspectos científicos. [...] Infra-mince seria o atributo ou adjetivo constituído por Marcel Duchamp para proposições estéticas, jogos semânticos, jogos com a linguagem, para o conjunto de sensações sutis que constituem suas 46 notas. Infra-mince seria, por exemplo, o momento último da passagem pelas roletas do metrô: nota $n^{\circ} 9$ (recto) - 'les gens/ qui passent au tout dernier moment Inframince'. [Seria também] o momento imponderável onde qualquer coisa que é selada, microscópica ou infinitesimal, acontece. Infra-mince [...] a sensação resultante da esfregação de um tecido de veludo pelas pernas: nota $n^{\circ} 9$ (verso) - "Pantalons de velours - leur sifflotement (dans la) marche par / frottement des 2 jambes est une / séparation Infra-mince signalée / par le son (ce n'est pas? un son infra-mince)'. O jogo da tactilidade e da sensualidade aí se torna aparente com toda evidência." FRANCA-HUCHET 1998, p. 20. 
só palavra: Inframince; com duas palavras, o infra se seguindo de mince: infra mince; e com o uso do hífen: infra-mince. Observa-se que o uso de diferentes grafias da palavra já faz dela um exemplo daquilo que descreve. Duchamp, brincando com as formas linguísticas, indica através de uma forma experimental e escritural aquilo que queria explorar teoricamente. Ora, ela seria, então, uma só palavra e concentraria todo o sentido de um só golpe, de uma só visada. Ao se utilizar do espaço entre Infra-mince, poder-se-ia até mesmo pensar na plasticidade da palavra, sua espacialização, sua temporalização, sua distensão. A terceira versão, com o uso do hífen - como traço de união ou o simples traço horizontal, pressuporia algo partido ou igualmente composto. Na Boîte Blanche (Caixa Branca) encontramos a nota "Procurar discutir sobre a duração plástica [...] Eu quero dizer tempo e espaço" (Duchamp citado por Sanouillet, Paris, 1975).

Praticamente, todas as Notas de Duchamp e suas intervenções podem ser definidas como um jogo linguístico que incluiria o clichê, o provérbio, o ditado e o aforismo, como se Duchamp quisesse distender um pouco as realidades físicas. "No nível da palavra, o duplo calembour de Duchamp é, na grande maioria dos casos, ancorado em uma dialética homofonia/homografia, homonímia/paronímia. Todas as interferências, relações e combinações som/sentido/grafia são utilizadas. " Diz Michel Sanouillet (1975, p. 147) que assinala o ardor subversivo de Duchamp, no que diz respeito à linguagem no nível da palavra e no da frase, que se recortam frequentemente no plano estrutural. Paul Matisse - autor do avant-propos do livro Marcel Duchamp Notes - encontrou-as após a morte do artista em 1968 e disse havê-las descoberto em um pequeno pacote de notas manuscritas; estas já datavam pelo menos de cinquenta anos precedentes. Em 1976 Teeny Duchamp, viúva de Marcel e mãe de Paul Matisse, Ihe pediu para colocá-las em ordem tal qual as teria encontrado, o que foi realizado. Paul Matisse relata que a ordem dessas notas, publicadas em Marcel Duchamp Notes, era quase exatamente aquela na qual as havia encontrado, pois Duchamp as conservava agrupadas em diferentes envelopes e pastas.

Dividi a obra em quatro sessões, a primeira condizendo ao conceito de Infra-mince. Na segunda estavam as que se referiam ao Grande Vidro e na terceira estavam aquelas que se reportavam a diferentes projetos. A última sessão era consagrada às notas dos jogos, palavras, aforismos, calembours e anagramas. (Matisse, 1980, p. 9) 
Paul Matisse intrigou-se com o fato de nenhuma explicação acompanhar essas notas e, parafraseando Duchamp, disse que as explicações não explicam nada, e que, talvez, o melhor fosse, como podemos ler no avant-propos, concluir o texto sem nenhum comentário. Mas as notas inspiram e aguçam os sentidos, e a "essência linguística do homem consiste naquilo que o faz nomear as coisas." ${ }^{4}$ (Benjamin, 2000, p. 146).

Nota $n^{\circ} 1$

O possível é um Infra-mince.

A possibilidade de muitos tubos de cores devirem um Seurat é a "explicação" concreta do possível como Infra-mince.

Possível implicando um devir - a passagem de um ao outro tem lugar no Infra-mince.

Alegoria sobre o "esquecer".

Nesta nota, observamos que certa mise-en-scène da realidade, uma pequena cena ou um pequeno espaço acolhem muitos tubos de cores esperando a possibilidade de se tornarem um Seurat. Possibilidade concreta de um possível como Infra-mince. Duchamp havia escrito suas Notas em torno dos anos 1930 e Seurat já era uma lembrança, pois morrera em 1891, aos 31 anos. Suas imagens luminosas eram fruto da técnica que inventara: o cromo-luminarismo, conhecido familiarmente por pontilhismo. Essa teoria vem inspirada pelos escritos do cientista Michel-Eugène Chevreuil sobre a lei do contraste simultâneo das cores. Outras teorias o influenciaram, como a obra crítica Gramática das Artes do Desenho (Paris, 1876) do crítico Charles Blanc, e a teoria científica das cores, de Ogden Rood (New York, 1879). Seurat interessava-se por teorias científicas e encarnava a nova geração de pintores e artistas que anunciavam novas concepções do espaço pictural. A teoria, cara a Seurat, o cromo-luminarismo, era fundamentada pela ótica e a ideia de que a luz resulta da combinação de muitas cores e, que um conjunto de pontos coloridos justapostos podem, observados de certa distância, recompor a unidade do tom e tornar a vibração luminosa com superioridade sensorial. Mas, por isso, Seurat foi condenado como positivista, sendo visto mais ao lado do laboratório científico que do ateliê do artista. Fala Duchamp: "Entre os impressionistas, Seurat me interessa

4 "(...)I'essence linguistique de I' homme consiste en ce qu'il nomme les choses". 
mais do que Cézanne [...] O único homem do passado que eu respeitava realmente era Seurat, que fazia os seus grandes quadros como um carpinteiro, como um artesão" (Duchamp citado por De Duve, 1984, p. 250)

No seu livro Nominalisme Pictural, Thierry De Duve se pergunta: Mas, por que Seurat? Por que a explicação não se desviaria e diria "a possibilidade de muitos tubos de cores se tornarem um Duchamp?". De Duve penetra em uma longa análise sobre a nota $\mathrm{n}^{\circ} 1$, não datada, e diz que o "tubo de cor ready-made é um quadro possível" (idem). É certo que a nota $\mathrm{n}^{\circ} 1$ nos fala dos muitos tubos de cores se tornando um Seurat como uma explicação concreta do Infra-mince. Contudo, poderse-á imaginar pontos de cores se tornando uma imagem, o jogo Infra-mince das explorações táteis da visibilidade. Seurat construindo uma imagem [um quadro] por gestos, admitindo a observação científica da luz para construi-la. O quadro possível é a imagem possível, aquilo que faz corte e recorte na vontade artística da operação técnica, celebrando a luz e a questão cara a Duchamp do écart e do acaso, - hasard - chamado também por ele de "Regime da coincidência"5 em uma de suas notas de sua célebre Boîte Verte (Caixa Verde) sobre seu trabalho Les Trois Stoppages Étalon. Seurat manifesta um salto no pensamento técnico, cuja referência à atmosfera luminosa de suas representações figurais funciona como um encontro físico entre os tubos de cores e a superfície pictural. O pintor parecia se interessar pelo inteligível em sua pintura pontilhista, mas queria torná-las sensíveis. Quando olhamos de uma distância justa um quadro - imagem - de Seurat, percebemos as modulações luminosas. Faculdade que a imagem tem de nos fazer perceber e repensar coisas, ultrapassando a concepção técnica e científica.

5 Sobre o Regime de Coincidências: insistência do interesse recorrente pelo acaso por Marcel Duchamp. O Regime de Coincidências aparece em uma nota autografada que se encontra na Boîte Verte, inventariada pelo número AM 1997-96 (23). A nota se intitula Regime de la Pesanteur (Regime da gravidade) e se encontra no Gabinete de Artes Gráficas do Centre Georges Pompidou, Paris, França. [...] Régime de la pesanteur Ministère des coïncidences, Département (ou mieux): Régime de la coïncidence Ministère de la pesanteur [...]. Regime da gravidade, Departamento (ou melhor): Regime da coincidência, Ministério da gravidade [...]". Duchamp se interessou muito pela queda, pela gravidade, o que podemos observar em vários de seus trabalhos, como o Trois Étoppages Étalon cujo acaso resultado da queda de três fios de um metro de altura tiveram suas formas fixadas em três réguas de madeira. Lembramos também o seu célebre trabalho Élevage de poussière, no qual a poeira que cai é cultivada, ao acaso. 
Considera-se de forma mais preponderante o conhecimento científico, fundado sobre a razão e a lógica, sobre a experimentação e a verificação como um método. Entretanto, podemos observar que existem outros caminhos para o conhecimento. Lembramos igualmente a abordagem que se desenvolve muito hoje em dia, na qual a ideia principal é dizer que o mais importante não são os objetos em si, mas a relação que produzirá certo número de fenômenos entre esses objetos. No entanto, poder-se-ia pensar em outras vias de abordagem do conhecimento que tratam da questão do sentido. Ora, o homem não se alimenta somente de pão, mas também de sentido, e isso é uma realidade bem objetiva: forças significantes existem no mesmo nível que as forças físicas, que as forças da mecânica newtoniana ou mesmo quântica. Em arte, podemos afirmar que existem formas de pensamento ou abordagens de conhecimento elaborando o mundo dos sentidos.

Nós, humanos, temos uma linguagem falada, que é ao mesmo tempo lógica e simbólica, gramatical, mas as palavras podem parecer dizer outras coisas que parecem dizer. Por exemplo, a natureza, os acontecimentos com os quais nos deparamos - um rosto, uma flor, uma árvore, um animal - tudo isso como linguagem muda que nos conta e inspira histórias. Linguagem muda não quer dizer que seria o non-sens, mas antes de tudo que é uma história que cabe a nós decifrar e perceber a dimensão poética em nossa relação com a realidade. Assim, parte da nota $\mathrm{n}^{\circ} 1$, "o possível implicando um devir - a passagem de um ao outro tem lugar no Infra-mince", nos integra a toda uma contingência de futuros possíveis, uma tênue percepção da superfície [pictural]; "a fenomenologia do Infra-mince seria uma fenomenologia do afloramento" (Didi-Huberman, 1997, p.167). O infra-mince poderia ser entendido como fragilidade, no entanto nos parece de uma grande exigência sensitiva e intelectível, pois é algo essencial e pontiagudo, que toca em questões essenciais do processo perceptivo.

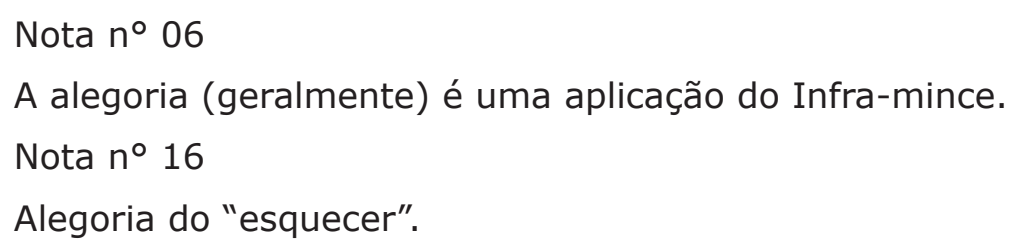

Walter Benjamin concebe a alegoria como uma chave do conhecimento. As alegorias, para ele, são para o reino do pensamento o que seriam as ruínas no do- 
mínio das coisas. "A consciência do caráter efêmero das coisas, e a preocupação de as tornar eternas, para as salvar, é um dos motivos mais fortes da alegoria" (Benjamin, 1985, p. 216). Alegoricamente o passado ressurge na experiência da memória, marcada pela imagem. Mas, o que esquecer? Não procuremos muito rapidamente responder o que seria a alegoria do esquecimento, mas lembremos de Walter Benjamin e sua posição sobre a memória involuntária, dizendo que somente poderá pertencer à memória involuntária o que foi realmente vivido, pois longe de restituir a duração integralmente conservada no sentido de Bergson, ela nos libera sobretudo percepções inconscientes. O recurso à alegoria, figura retórica que consiste em representar uma ideia abstrata através de símbolos ou imagens poéticas, parece nos propor para o esquecimento uma operação de sentido temporal. O termo alegoria, na nota, possui um significado bem mais amplo do que em primeira instância, pois se aplica a um certo tipo de operação de leitura. Um texto é dito alegórico quando propõe, em uma primeira leitura, um certo significado, quando na verdade recobre um outro; assim, o leitor deverá perceber os jogos e as transposições necessárias. Oferecendo um duplo jogo à compreensão, a alegoria tende a ocultar o alvo semântico que constitui a leitura de um texto e a colocar a produção sob o signo da transposição das aparências. Estávamos em tubos de cores em devir de se transformarem em quadros de Seurat, e o possível seria o lugar do futuro, onde o devir da imagem aí encontraria sua concretude. As passagens dos tubos para a imagem e a imagem tecnicamente feita pelas cores, resultam em modulações Infra-minces. Duchamp parece propor o ready-made [tubos de cores] como proposição para pensar a pintura, mas também para esquecê-la no sentido em que esta era vista e praticada pelo meio artístico dominante do início do século XX. Posto isso, percebemos uma dimensão espacial - o devir do quadro, da imagem e a possibilidade de um tubo de cor se tornar um Seurat, uma espacialidade concreta do possível em uma dimensão temporal. O Infra-mince é sensorial, é perceptível infinitesimalmente, contudo existe um misterioso esquecimento. Infra-mince e intervalos imperceptíveis de esquecimento entre dois fenômenos.

Uma lacuna remetendo à substância do tempo é o que parece nos remeter a alegoria do esquecimento. A lacuna como um écart Infra-mince que espacializaria algo entre a lembrança e o fato, lacuna como uma falta, que por sua vez, poder-se-á ser procurada e encontrada. Mas encontrá-la - ou sua emergência na consciência 
- nos parece na nota 06, estar acompanhada pela imaginação, se voltando para a ficção, para o inventivo. A alegoria, sendo metáfora continuada, dizendo uma coisa para se fazer entender outra, encontra no universo duchampiano um lugar de confluências, pois observamos muitas transposições discursivas. Se a alegoria é uma aplicação do Infra-mince, vamos considerá-la pois como uma fenomenologia estilhaçada, mas não necessariamente dispersa, pois a relação com o tempo permanece no enunciado; é o caminho que intentamos seguir aqui: o campo polissêmico do esquecimento é atravessado pelas formas alegóricas, que modificam e induzem a construção do esquecido que, embaralhado, reconstrói suas partes como as peças de um quebra-cabeças.

Arriscamos dizer que olhamos para as Notas do Infra-mince como um campo de convergência inter-relacional e fenomenológico. Existe um fenômeno que tem como visada criar enunciados em uma tonalidade conceitual, mas com uma face que quer habitar o espaço para senti-lo, descrevê-lo, compreendê-lo. É preciso primeiramente ser espacial. O Infra-mince não procura a clareza em suas proposições, mas ganhamos terreno, caminhamos e avançamos quando recebemos também as sombras do segredo, da opacidade de uma frase que nos é devolvida com intempestiva estranheza, quando nos abismamos, nos perdemos e assumimos a obscuridade e a ambiguidade. Assumimos o obscuro pois sentimos que os fenômenos se justapõem em muitos planos que, por vezes, soam apenas como brincadeiras do non-sens, mas que bem sabemos, para Duchamp, as questões não se satisfazem com uma única resposta.

Entre alegoria e esquecimento se trata de uma polaridade: por um lado esquecemos algo, apagamos, por outro alegorizamos, pensamos sob a forma figurada, ficcionando. Toda a pintura poderia ser entendida através desta dialética. Uma imagem pede para ser encontrada. Momento para rememorar o instigante quadro de Marcel Duchamp La Mariée. ${ }^{6}$

Ele partira para uma viagem no verão de 1912 a Munique após a atmosfera incômoda que suscitou o seu quadro O Nu descendo a escada. Ficara triste e entediado

6 Marcel Duchamp, Mariée, 1912 Huile sur toile, 89,5 x 55,6 cm Philadelphia Museum of Art, Philadelphie The Louise and Walter Arensberg Collection, 1950 - Schwarz n²53. É a imagem disponível em: http://www.wikiart.org/en/marcel-duchamp/transition-of-virgin-into-a-bride-1912 
com o diálogo entre o quadro e o meio artístico parisiense. Seu horizonte de trabaIho se viu barrado, mal compreendido, o que o fez mergulhar em uma melancolia particular. A escolha por Munique foi justamente por ser um centro importante da prática da pintura na Europa. Muitos artistas ali estavam ou por ali passavam; Klee, Kandinsky, De Chirico, Delaunay e, Marcel Duchamp disse, ele mesmo, que sua estadia em Munique teria sido uma liberação completa para ele. Visitando os museus de Bâle, Viena, Dresde, Berlim foi atingido pelo novo ambiente.

Foi muito marcado por uma Vênus de Cranach, cuja representação carnal o impressionou bastante. Lá, traçou o plano geral para um grande trabalho, de grande formato, que o ocuparia por muito tempo na sequência, com problemas técnicos desafiantes para resolver. Eram as premissas do Grande Vidro. ${ }^{7}$ Ele realiza, junto à Passage de la Vierge a la Mariée, o quadro La Mariée, em 1912, cuja execução extraordinariamente bem cuidada, inspirada na técnica pictural alemã - a do pintor Cranach em particular - revela um novo interesse artístico, ajudando-o a superar as dificuldades que o perpassavam desde Paris. "Amo estes Cranach... os adoro [...]" dirá ele. "A natureza e a matéria de seus nus me inspiraram para a cor da carne ${ }^{\prime \prime}$ [...] Ele se impregnou dos aveludados dos quadros, mas também de seus glacis ${ }^{9}$ uma técnica pictural que fazia surgir a luz da profundidade inerente à tela. Para Robert Lebel, essas encarnações "fazem mergulhar até as profundidades do inconsciente orgânico" (Lebel, 1966, p.15). Esse quadro se tornaria a parte superior do Grande Vidro. ${ }^{10}$

É um pequeno quadro vertical, de $80 \times 55 \mathrm{~cm}$, que figura uma representação irreal, pintada, portanto com um extremo realismo. Foi executado nos tons cinza, bege e

7 Le Grand Verre, O Grande Vidro, obra de Marcel Duchamp cujo nome original era La mariée mise a nu par ses celibataires même foi realizada entre 1915 e 1923 em New York. Óleo, verniz, folha de chumbo e poeira entre dois painéis. Suas dimensões são $277.5 \times 175.9 \mathrm{~cm}$ e se encontra no philadelphia Museum of Art, USA. Imagem disponível em: https://en.wikipedia.org/wiki/The_Bride_Stripped_Bare_by_Her_Bachelors,_Even.

8 Radio France. Marcel Duchamp: A bruit Secret. Une vie une oeuvre. Uma emissão de Bárbara Turquier e Nathalie Batthus. 23 de novembro de 2013.

9 O glacis é uma técnica pictural inventada pelos pintores alemães do Renascimento, entre os quais Cranach L'Ancien (1472-1553), Albretch Dürer (1471-1528) e Hans Holbëin (1465-1524).

10 A nota $n^{\circ} 13$ e a citação de Robert Lebel, são do Dossiê Pedagógico Marcel Duchamp et la Peinture Même. Direction des Publics. Texte Marie Jose Rodriguez. Exposição no Centro Georges Pompidou. Paris. 24 de setembro de 2014 a 5 de janeiro de 2015. 
Alegaria de esqueamento

Ca manizé
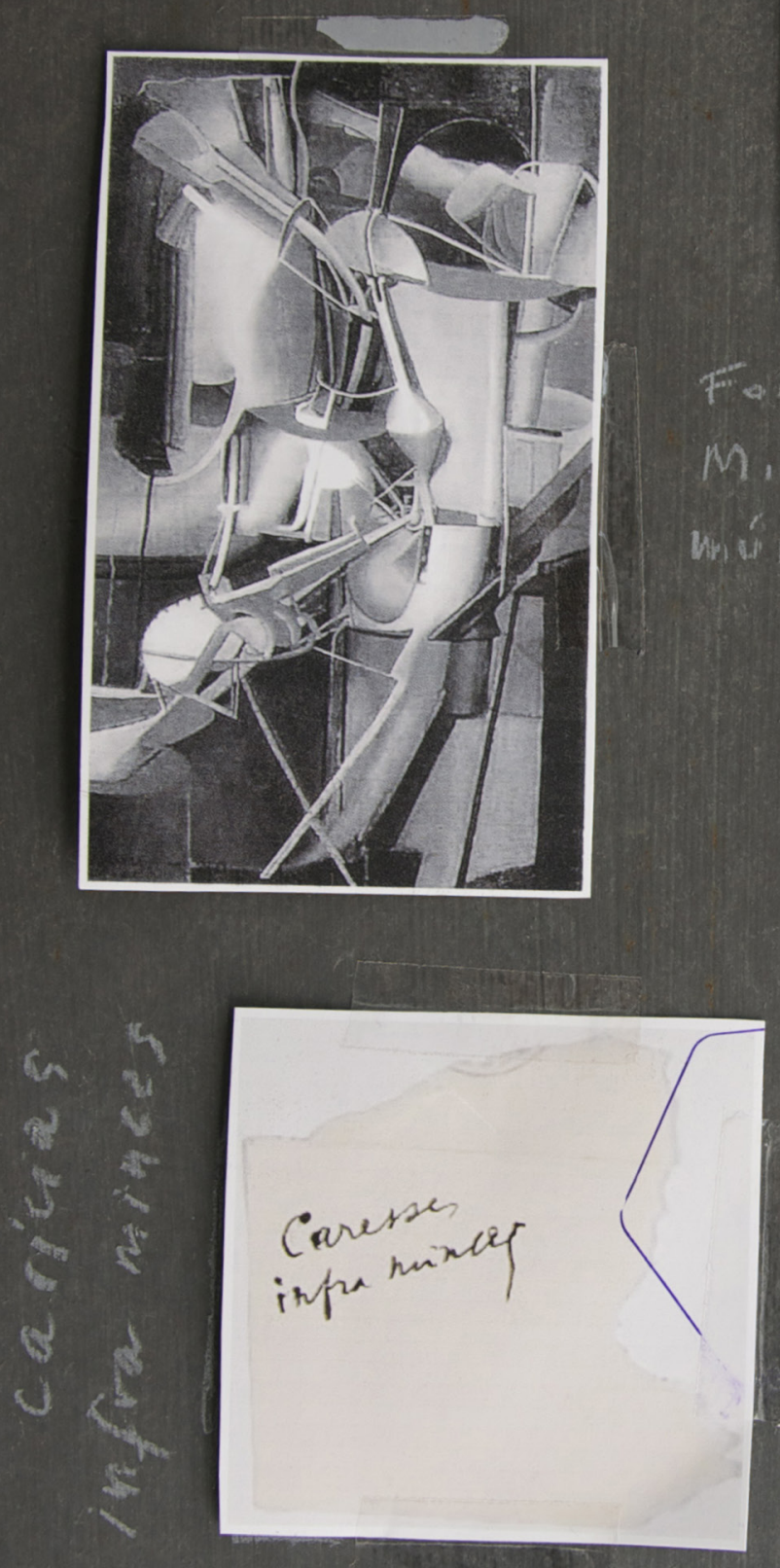

(c)

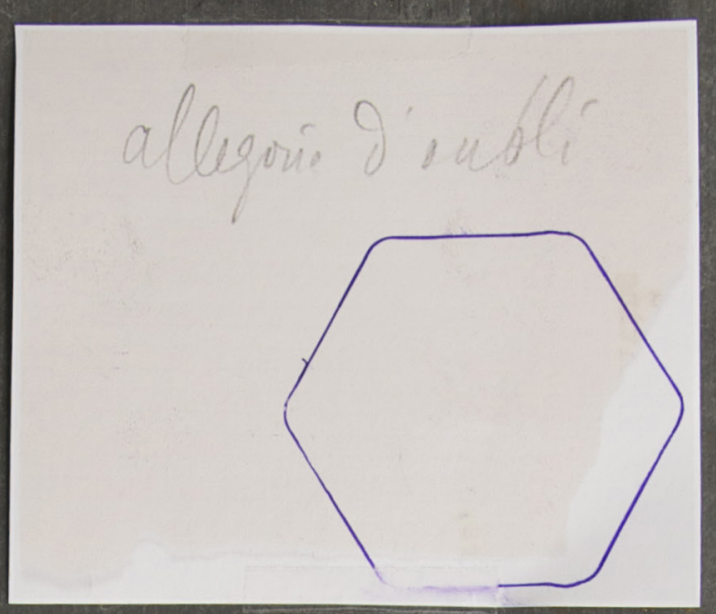

Fofo de Raihared Hamiltwon/1967 M. Dassimande o estuch do múltaplo Oculist Witnesses.

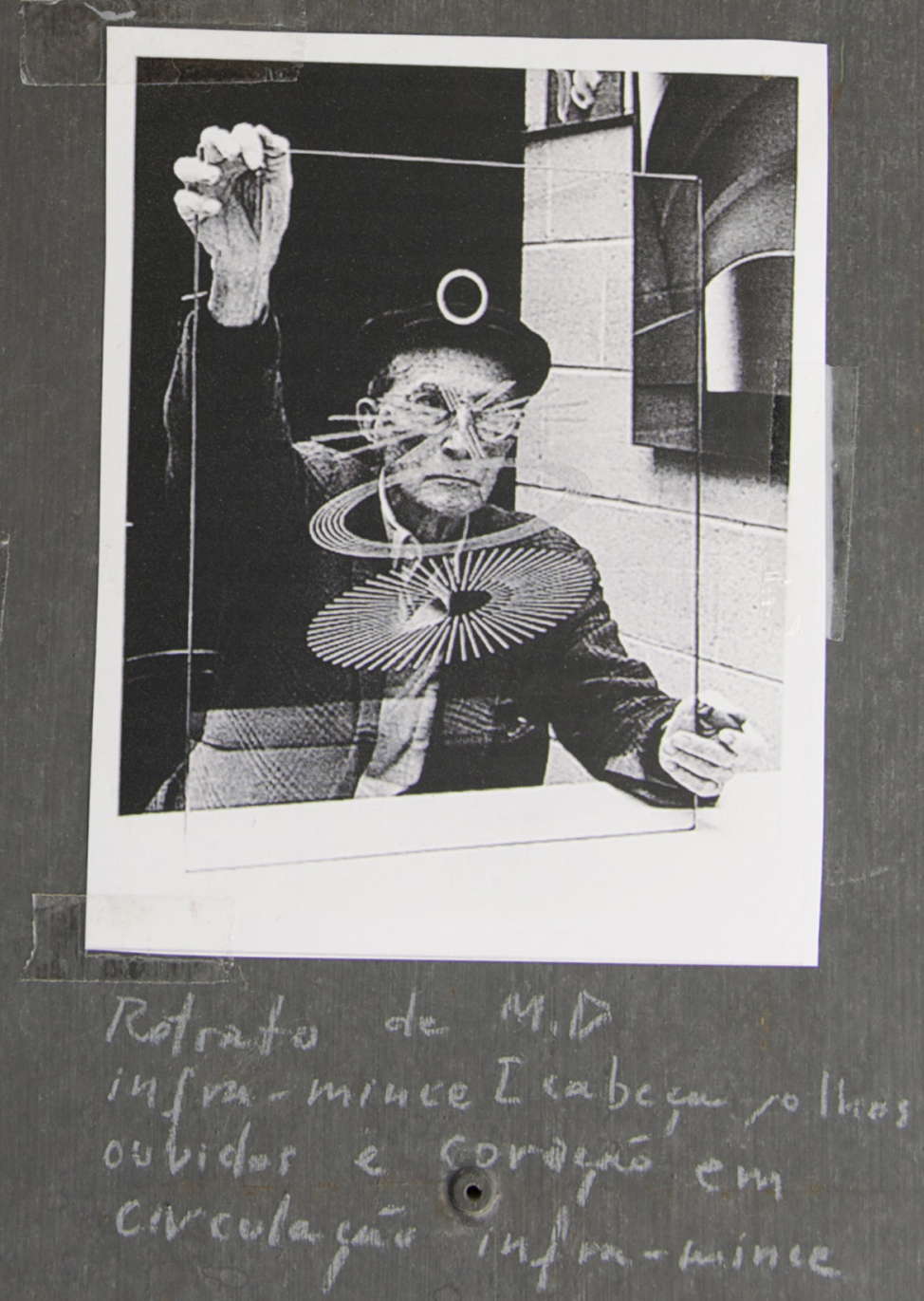


rosa e a figura parece resultar da hibridação de órgãos e de elementos mecânicos que parecem metamorfosear a anatomia - órgãos femininos -, evocando também um inseto, algo maquínico. A sexualidade que dele irradia é evidenciada ainda pela sobreposição do título, remetendo a uma mulher. André Breton escrevera:

Em sua base, a noiva é um motor, mas antes de ser um motor que transmite sua potência tímida, ela é sua potência tímida em si, uma espécie de automobiline, uma essência de amor que distribuída pelos cilindros bem fracos conduziu as fagulhas de sua vida constante, serve à realização da virgem que chegou aos termos com o seu desejo". ${ }^{11}$ (André Breton citado por Lebel, 1966, p. 88).

La Mariée é um quadro que evoca, além de um corpo estilhaçado em movimento, a sexualidade implícita. Paradoxalmente, parece nos lembrar da mecânica do desejo entranhado, sua invisibilidade Infra-mince. Uma maneira poética para Duchamp transmitir as suas intuições, dizendo mesmo que não queria ser um pseudo Cézanne e que havia começado a utilizar o seu espírito no lugar dos pincéis. Isso correspondia bem à sua ideia de pintura, uma ideia modificada de pintura, que abria suas possibilidades para uma maneira de realizá-la diversamente. Supõe-se a questão: como Marcel Duchamp colocou para si a questão da pintura? Considerar a forma de interpretação da Mariée e de La Mariée estilhaçada expõe a ausência e a presença simultâneas de um espaço e de um tempo. O corpo se constitui ali como questão primordial. A dissimetria e a dessemelhança estão nessa obra expressas e constituem seu destino diante do seu sentido espacial e temporal. A forma lhe permitiu o movimento, preservando sua profundidade e sua superfície fervente. Ela criou a terceira dimensão encontrando sua espacialidade e temporalidade próprias, mas sem querer reduzi-la a uma inventividade apenas geométrica. Assim como Proust, ele temporalizou a forma, o que nos parece ser uma luta laboriosa contra o esquecimento; é o momento em que a profundidade se torna temporal, que permanece e que podemos encontrá-la; em sua espessura, em sua opacidade, em seu grão, em sua substância. Coisa que a pintura e a escrita são suscetíveis

11 "la marié a sa base est un moteur, mais avant d'etre un moteur qui transmet sa puissance timide, elle est sa puissance timide meme, une sorte d'automobiline, une essence d'amour qui distribué aux cilindres bien faibles a porté des etincelles de sa vie constante, sers a l'epanuissement de la vierge arrivé au terme de son désir". BRETON, André. Phare de la mariée, In: Minotaure, n06, 1935, citado por LEBEL, Robert. Sur Marcel Duchamp, opus. cit., p. 88-94. 
de restituir. La Mariée tem seu enigma. A palavra enigma e não mistério. Ficamos desamparados diante daquelas formas que autorizam ou não a portar sobre elas um olhar explosivo.

Nota $n^{\circ} 2$

Analogie Infra-mince

Nota $n^{\circ} 46$

Infra-mince

Reflexos de luz sobre diferentes superfícies mais ou menos polidas.

Reflexos não polidos dando um efeito de reflexão - espelho em profundidade - poderiam servir de ilustração ótica para a ideia de Infra-mince como "condutor" da $2^{a}$ para a $3^{a}$ dimensão.

Irisação como caso particular do reflexo.

- Espelho e reflexão em um espelho máximo dessa passagem da $2^{a}$ para a $3^{a}$ dimensão - (incidentemente / por que os olhos se "acomodam" em um espelho?).

A pouco fizemos a pergunta: como Duchamp colocou para si a questão da pintura? Agora, ficamos a imaginar como ele pensava a questão da aparição, do fenômeno em si, posto que a questão da percepção das coisas ínfimas aparece como um dado efetivo das suas notas. Sendo a analogia a semelhança entre coisas diferentes, encontramos a polaridade da reflexividade. Uma covariação de reflexos: vejo o mundo que está inteiramente refletido em minha consciência, a reflexividade sendo, neste texto, uma referência para o polo dialético da analogia Infra-mince.

Além do aspecto fenomenológico que atribuímos à nota, sabemos que Duchamp gostava da matemática, a reflexividade sendo nesse campo uma relação binária em que cada elemento está em relação consigo próprio. Marcel Duchamp aparece assim como um artista que compreendia a paisagem de seu tempo e os conceitos fundamentais que o atravessaram. No século XX, o conceito de reflexividade assim como o transcendental da consciência de si foram colocados em discussão através de diferentes maneiras por inúmeros pensadores; pela fenomenologia por Merleau -Ponty, pela hermenêutica por Heidegger, Gadamer e Taylor, de forma pragmática por Habermas ou analítica por Tugendhat e pela Escola de Frankfurt. Marcel Duchamp apresenta a reflexividade em suas notas com a liberdade artística que lhe convinha, todavia com ironia. A ironia amorosa que compreendemos como a forma de um jogo alumiado. Outra questão aqui seria: qual é a relação que Duchamp pode erigir sobre a consciência de si compreendida como modo de reflexividade, 
já que em suas notas é uma palavra subjacente? Certamente não seria o momento para se analisar as teorias dos filósofos acima, mas encaminhando o raciocínio sob a égide da fenomenologia da percepção da imagem, do tempo, da coisa e da phantasia, admitimos que seu modo de operação artística traz o caráter distinto de intuitividade reflexiva e, por vezes, pretensamente científico. ${ }^{12}$ Face a face com o caráter posicional da percepção, intervém aqui obliquamente a questão da individuação. Por isso, às vezes ficamos sem voz diante das notas enigmáticas do artista. Poder-se-á pensar que apesar de todo o mistério e radicalidade guardados nessas pequenas notas, um diálogo entre o artista e a filosofia aí se faz. Mas tendemos a olhar pela diagonal e nossa imaginação pode se tornar eloquente.

Irisação como caso particular do reflexo. Claro enunciado que nos permite relacionar a experiência sensória com o exercício do Infra-mince. Ocasião para a observação sobre substâncias sensoriais e a mudança da atenção para aspectos destas que são usualmente negligenciadas. Duchamp expõe o lado material da luz, a sua irisação colorindo um reflexo Infra-mince. Uma hipótese: a irisação vista por Duchamp através das gotículas do jato de uma mangueira que molha flores de um jardim em uma tarde de verão. De fato, não podemos negar que o Infra-mince contém em sua linguagem uma indagação contemplativa e inútil trazer para a lógica convencional da percepção ordinária sua dimensão flexível contendo a tênue materialidade das coisas ao redor. Um possível Infra-mince: Irisação reflexiva - água saindo entre os dedos apertados induzem pressão produzindo um jato Infra-mince. Cores surgem do movimento atravessador da luz em gotículas que se estilhaçam.

No final da Nota $\mathrm{n}^{\circ} 46$ nos defrontamos com a última frase: "Espelho e reflexão em um espelho máximo dessa passagem da $2^{\circ}$ para a $3^{\circ}$ dimensão - (incidentalmente / porque os olhos se "acomodam" em um espelho?)". Difíceis triangulações reflexivas. Seria o espelho um devorador de imagens? Ao mesmo tempo em que olhamos para ele sabemos que não estamos lá, acomodamos o que vemos no espelho, nos deixamos refletir. Vemos parte de nossa imagem em uma superfície, a superfície é clara; vemos reflexividade na superfície mais ou menos polida, pois

12 Duchamp era um admirador das ciências, da matemática e em algumas de suas notas - além do conjunto do infra-mince - observamos desenhos com números e perspectivas como se fossem equações que desejassem demonstrar, com humor, uma dimensão científica, lúdica e sensível. 
mesmo assim alguma coisa é engolida por ela ao mesmo tempo em que é devolvida para o olhar. O espelho seria um espaço topológico de elasticidade e da circulação entre o dentro e o fora, as imagens se diluindo no corpo especular. Todavia, um ponto que atravessa nossa subjetividade poderá criar uma terceira dimensão, pois estamos desde sempre levando sempre o dentro para fora e o fora para dentro e o espelho é uma das formas mais simples de abordar o reflexo. É um objeto do cotidiano que reflete o mundo exterior; em um pequeno espaço reduzido, ele encerra em sua unidade as passagens das imagens e muitas vezes a deforma, iludindo. Vai interrogar a imagem do sujeito, que é um nó central das reflexões sobre a identidade, o conhecimento e a representação de si mesmo. No reflexo, o espelho é analogia Infra-mince quando identifica e difere.

Não podemos nos esquecer dos efeitos que o espelho metaforiza e impõe à linguagem, sabemos que são vivenciados os efeitos de especularidade, mise-en-abyme, duplicação. Jogando entre a distância e a separação, o espelho produz uma situação de troca entre a imagem e o reflexo e como objeto de simulacro serve como uma luva para a ficção, a phantasia e a imaginação. Por isso se tornou um objeto tão importante do léxico Infra-mince, se inscrevendo na proposta de Marcel Duchamp do entre-dois, da relação e da mediação. Um modelo que oscilaria entre a contemplação e a ação.

Jean-François Lyotard faz sua a noção duchampiana de "miroirique", um neologismo francês intraduzível, derivado da palavra miroir (espelho) querendo demonstrar que este dá lugar a transformações e deformações as quais são submetidas toda forma mirada em uma superfície especular. Estas - Duchamp nos permitiria? - podem ser entendidas como maquinações; o espelho como uma máquina reprodutora, mimética e dissimuladora; aqui o écart novamente. A distância e o estranhamento produzidos pelo movimento especular próprio a toda superfície refletora. O dispositivo reflexivo e refletor abre na cena Infra-mince uma singular profundidade, mostra sua fidelidade transformante, a que conduz toda relação aos afetos de disjunção ou de inclusão, pois faz hesitar nossa situação lógica e cognitiva, assim como a porta do 11 rue Larrey de Duchamp: aberta mas também fechada. Algo, portanto, difere, no sentido de temporalizar, de especializar naquele em que se produzem as diferenças.

Maquinações, o espelho como uma máquina reprodutora e mimética: a distância 
e o estranhamento produzido pela imagem refletida em todo objeto espelhante ou similar. "O Grande Vidro de Marcel Duchamp é "miroirique": os espaços da mariée e dos solteiros se entreolham, mas eles ficam dessemelhantes, nem superpostos nem congruentes". (Lyotard, 1977, p.52) O Grande Vidro é um cristal do tempo. Lembramos aqui que Gilles Deleuze pensou o tempo - dentre outras coisas através da imagem-cristal. A imagem cristal não é o tempo, mas nós vemos o tempo no cristal. Existem diferentes estados do cristal segundo os atos de sua formação. Para o filósofo, cada um de seus estados de formação é chamado um cristal do tempo. Deleuze utilizou o vocabulário do mineral para batizar a imagem particular que segundo ele é própria a transparecer o tempo: a imagem-cristal. Associou-a ao cinema, que teria a virtude de entrar em coalescência - adesão das partes que estavam separadas - , realizar e espacializar qualidades plásticas, as quais podemos descrever.

Espelho em profundidade: como salvar ou preservar a profundidade do sentido, de seu lado fervente? Infra-mince: déjà vu. A impressão de viver um tempo perceptivo em duplicata. O passado parecendo tomar a forma do presente, mas não um passado que seria passado, nem rememoração e lembrança, mas o passado que seria o passado desse presente, coexistindo com a percepção e a vivência da experiência. Assim, a ideia de um tempo não cronológico que artistas e pesquisadores conhecem e trabalham.

Ocorre-me a lembrança da voz pelo Infra-mince. Entre o Infra-mince e a convergência inter-relacional dois polos, em ocorrência, entre o conceito de Infra-mince e tudo o que dele ressoa, entre o eu interlocutor acontece o fenômeno que cria linguagem. Esta convergência interrrelacional é muito estudada em linguística, e isso perdura no tempo de maneira fascinante. Falamos um ao outro e surrupiamos [um e outro] algumas de nossas propostas discursivas, o que faz que algo perdure um pouco em minha voz.

Infra-mince e escuta da voz: a voz é vibratória e algumas vezes acariciante [Inframince gravitando na esfera do non-sens, na qual ficamos sem voz].

Marcel Duchamp propôs o Infra-mince como uma experiência alterada, uma forma de se deixar intoxicar pela matéria e pelos sentidos através dela vivenciados. A arte lhe permitiu viver na suspensão de uma multiplicidade de questões: é papel do artista inventar uma linguagem para preencher o espaço daquilo que não exis- 
te, o artista cria então um infigurável.

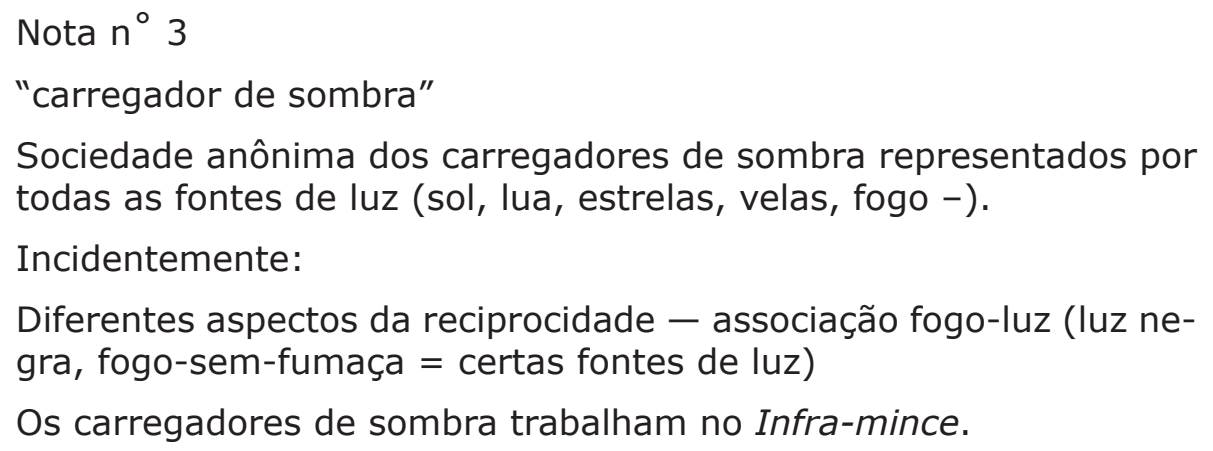

Interpretar sintomas é trabalhar nas sombras. Poder-se-á pensar na elaboração dos carregadores de sombra como materialização dos sintomas iluminando o conhecimento de si mesmo. Eles - a sociedade anônima - carregam sombras mas são representados por todas as fontes de luz. Porém, incidentemente, os diferentes aspectos da reciprocidade criam associações muito peculiares, como a luz negra, ou um fogo sem fumaça.

Sintomas são manifestações da sombra, pois emergem das profundezas do inconsciente para o mundo corpóreo e, podemos nos considerar, todos, carregadores de sombras. As assustadoras ou redimidas sombras que trabalham os carregadores desde o seu mais profundo interior são Infra-mince. Mas quão simbólica é a nota $\mathrm{n}^{\circ} 3$ ? A chave de seu segredo parece-nos estar em sua recepção intuitiva mais do que em sua análise. O lado escuro está junto ao lado luminoso e a dependência desses dois opostos são tão complementares! Diferentes aspectos da reciprocidade podem parecer polaridades que se excluem, mas que percebidas mais atentamente, formam uma unidade.

\section{Medida de sombra Infra-mince.}

Difícil para nós negar a dimensão enigmática e simbólica de Marcel Duchamp. Herman Parret discute como "estamos habituados às tantas interpretações de Marcel Duchamp possivelmente hermenêuticas: esotéricas (Breton), alquímicas (Sanouillet, Lebel, Pontus Hulten, Linde), freudianas e junganas (Schwarz), cabalísticas (Burhnham), vergonhosamente religiosas (Calvesi) docemente simbólicas (Paz)..." (Parret, 2010, p. 17). Herman Parret nega o lado simbólico da obra de Duchamp, 
admitindo mais o seu lado maquínico e astucioso. É todo o contrário de nossa argumentação desde o início. Não acreditamos que um artista possa criar tal noção sem estar consciente da sua intencionalidade artística, de seu erotismo evidenciado, de suas intenções silenciosas, de sua linguagem subversiva que, acima de tudo, criava dúvidas sobre tantas certezas. Logo Duchamp? Que observava atentamente os signos de sua época, desconfiando do olhar para as coisas perfeitas e considerando o lado sombrio e desafiador em suas experiências? Parret menciona:

...desconfiança da alegoria, do simbolismo. O significante não significa pela convenção simbólica como linguagem "o sério", arte mensagem ou arte expressiva, mas ele significa pela chance das associações metonímias [...] a arte não conta nada, não reenvia ao nada, ela sintagmatiza o côncavo e o convexo, o pleno e o vazio, o pênis e a vulva segundo a geometria indicial do Infra-mince (Parret, 2010, p.19).

A lição do Infra-mince estaria perdida para sempre em análises frias e muito circunscritas como esta. Se o erotismo era para ele a questão pontual, como defini-lo apenas como algo que não conta nada e não reenvia ao nada? Qual a frase ou obra que seja que não reenvia a nada? Como leitores e espectadores somos livres para entender e decifrar o Infra-mince sem fechá-lo em categorias semióticas ou outras categorias.

Proponho, terminando esta passagem pela nota $n^{\circ} 3$, uma constelação semântica pinçada nas notas duchampianas do Infra-mince, como: lupa [para o tocar], sombra, fogo, luz, sol, lua, estrelas, vela, luz negra, reflexo do espelho, teia de aranha, cores, seda, veludo, água, chumbo fundido, papel cavado, transparências, líquidos, creme, carícias, ar, homens, árvores, barcos, cheiros, reflexos, flor, voz, pantalon, molde, fuzil, flecha, animal, vegetal, olho, calor, similaridade, pintura, papel carta, dia, cone, foto, películas, etc.

\section{Pensamos no cultivo do non-sens}

Todo conhecimento se presta a um ato de nascimento. No Regime de Coincidências não nos deparamos com um modo de pensamento científico, rigoroso, organizado. Lembremo-nos de Husserl que criou um sistema de interrogação do sentido de forma admirável. Interrogar-se sobre o mundo do sentido e o mundo do simbólico, que é a linguagem do inconsciente. Etimologicamente, símbolo vem do grego simbolen, que quer dizer aquilo que reúne, que vem unir, ligar o visível e o invisível, 
o consciente e o inconsciente, o imaginário e o mundo real. A arte seria, dentro desse exposto, como um espaço de abertura que se cria entre o mundo do sentido e o mundo da realidade ordinária. Em suas Notas, Duchamp parecia explorar algo que organiza e estrutura o mundo do sentido e os meios de contato com este.

Escolhi propositalmente a palavra mince que é uma palavra humana e afetiva e não uma medida precisa de laboratório. O barulho ou a música feita pela friccão do veludo de uma calça ao nos mover está ligado ao conceito do Infra-mince. O vazio no papel entre frente e verso de uma fina folha... A estudar!... É uma categoria a qual eu me dediquei muito durante os dez últimos anos. Penso que através do Infra-mince é possível ir da segunda à terceira dimensão (Duchamp citado por Dworkin, 2013, p. 18). ${ }^{13}$

Este testemunho nos faz acreditar que Duchamp parecia levar a percepção artística a novos limites. Algo entre a concretude de uma mesa [a linguagem] e o tabuleiro de xadrez sobre a mesa [a atenção inconsciente ao jogo]. Por isso, algo que excedera a arte; passamos para a hipérbole do fora de si, da experiência limite. Mas, quase sempre, no jogo, algo se intensifica, de um golpe somos tomados por uma vertigem, ficamos cegos. Como um problema do tempo, o jogo se jogando e se distendendo, mas para tentar encontrar os lances. A experiência está mais do que nunca ativa. A partir dessa apreensão, nós queremos então fazer abstrações, reflexões, e, finalmente, o laço entre o sensorial e o senso se mostra algo complexo que sobrevive sobre idas e voltas permanentes. A arte é um motivo para o saber, que produz certa relação com o tempo e que consiste em produzir sentido, sensação, pensamento. E Duchamp esteve em suas notas à procura de palavras para descrever o que se passa em torno de nós, aquilo que da invisibilidade pode ser escrito.

Viver segundo a nuance, como disse Barthes, viver para produzir nuances, para inventar pequenas diferenças; é um projeto muito difícil, uma ética muito exigente, mas me parece algo inevitável hoje em dia. E... uma vez que abrimos os olhos, que erguemos os

13 "J'ai choisi exprès le mot mince qui est un mot humain et affectif et non une mesure précise de laboratoire. Le bruit ou la musique faits par un pantalon de velours côtelé comme celui ci quand on le fait bouger est lié au concept d'Infra-mince. Le creux dans le papier entre le recto et le verso d'une fine feuille... A étudier! C'est une catégorie dont je me suis beaucoup occupé pendant ces dix dernières années. Je pense qu'au travers de l'Infra-mince, il est possible d'aller de la seconde à la troisième dimension" [Tradução nossa]. 
ouvidos, que degustamos as sutilezas do Infra-mince, bem no fundo, o invisível, o nada, ou o quase nada ocupa todo um espaço, um lugar, e isso é o seu triunfo. (Thierry Davila, entrevista, Radio France Culture).${ }^{14}$

O Infra-mince, pois, é tudo isso: relevar singularidades naquilo que aparece e desaparece diante de nós, abrir os olhos para facetas da matéria que não nos são apreensíveis.

\section{Referências}

BENJAMIN, Walter. Origine du drame baroque allemand. Paris: FlammarionChamps, 1985. Sur le langage. Oeuvres I. Paris: Gallimard, 2000.

DIDI-HUBERMAN. Georges. L'Empreinte. Catálogo de exposição. Paris: Ed. Centre Georges Pompidou, 1997.

DUCHAMP, Marcel. Duchamp du Signe. In: SANOUILLET, Michel (Org.) Écrits. Paris: Flammarion, 1975.

DE DUVE, Thierry. Nominalisme Pictural: Marcel Duchamp la peinture et la modernité. Paris: Ed. de Minuit, 1984.

DWORKIN, Craig. No Medium. Cambridge MA: The MIT Press, 2013.

FRANCA-HUCHET, Patricia. Infra-mince, Zona de sombra e o tempo do entre dois. Porto Arte. $\mathrm{N}^{\circ}$ 16, Porto Alegre: Revista do PPGAV da UFRGS, 1998.

HULTEN, PONTUS. Marcel Duchamp: work and life. Cambridge: The MIT Press, 1993.

LEBEL, Robert. Sur Marcel Duchamp. Paris: éditions Trianon, 1959; re-edição Centre Pompidou/Mazzotta, 1996.

LYOTARD, Jean-François. Les Transformateurs Duchamp. Paris: Ed. Galilée, 1977.

MATISSE, Paul (Org.). Marcel Duchamp Notes. Paris: Centre National d'Art et de Culture Georges Pompidou, 1980.

14 Tradução nossa de trecho da entrevista de Thierry Davila por Alain Veinstein na ocasião do lançamento do seu livro De L'Infra-mince. Radio France Culture 29 nov. 2010. 
PARRET, Herman. Duchamp's TRANS/formers. Prefácio. Leuven: Leuven University Press, 2010.

RADIO FRANCE CULTURE trecho da entrevista de Thierry Davila por Alain Veinstein na emissão Du jour au lendemain na ocasião do lançamento do livro De L'Inframince em 29 de novembro de 2010.

RADIO FRANCE CULTURE. Marcel Duchamp: a bruit Secret. Une vie une oeuvre. Uma emissão de Bárbara Turquier e Nathalie Batthus em 23 de novembro de 2010. 